\title{
INVESTIGATION OF THE STATE OF THE RADIATION CONTROL SYSTEMS AND THE ACTIONS OF THE COMPETENT AUTHORITIES AND THE POPULATION IN THE EVENT OF A CHANGE IN THE RADIATION BACKGROUND IN BULGARIA
}

\author{
Nikolay Todorov DOLCHINKOV \\ „Vasil Levski“‘ National Military University, Veliko Tarnovo, Bulgaria \\ n_dolchinkov@abv.bg
}

\begin{abstract}
After the Chernobyl and Fukushima accidents, the monitoring of radiation at a real-time and timely publishing the information about the changes in order to inform the population has a major importance nowadays. In Bulgaria this system is working since 1997 to nowadays, and over the years it has been retrofitted twice. I made a research among 38 specialists in this field, 158 others trained to operate in a nuclear, chemical or other accident and 196 randomly selected representatives from the society. The results of my survey show the state of the radioactive background control systems and the knowledge about their working process by the specialists and also the population. The number of people that are familiar with the National Automated System for Continuous Control of the Radiochemical Background and the Radiation Population Disease Forecasting System in the Event of a Major Nuclear Accident of the National Institute of Meteorology and Hydrology is extremely low. The responses to the issues of coordination of the responsible authorities and agencies give us a real picture of the population's interest in the real situation of a radiation. The picture in the assessment of the coordination between the departments which announce the changing in the radiation situation on the territory of Bulgaria is similar. Most of the people who take part into the survey did not make suggestions on improving the situation, but on the other side there are also very reasonable and argumented ones. First of all, the participants indicate an increase in the population training about the real problem and conduction of such a regular and quality exercises.
\end{abstract}

Keywords: monitoring, research, assessment, coordination, population training

Radioactive contamination is a process of permanent pollution with radioactive particles, mostly happened as a result to a nuclear explosion. These particles pass through the atmosphere from the explosion and then fall to the ground. They fall into the soil, water and air and lead to radioactive contamination of the environment [1]. Particularly dangerous for humans are radioactive wastes with radioactive isotopes of iodine, strontium and cesium. Iodine accumulates in the thyroid gland, strontium - in the bones, and cesium - in the muscles, which is why the human organism undergoes continuous radioactive irradiation.

Radioactive contamination has general national and international sense and it is related to the increasing of measures for prevention from accidents, resulting from the use of nuclear energy for peaceful purposes and in the military sphere. In a 
view of the increasing activity of terrorist organizations and the unstable situation in the region, the likelihood of nuclear terrorism has increased. Because of its geopolitical location, the nuclear power planned and operating in Bulgaria and in the countries thah are close to us, can have a great impact on the surrounding natural radioactive background. Optimizing and managing the existing radiation monitoring systems will lead to increasing of the nuclear security in Bulgaria and adequate measures and decision in order to improve the protection of the population from radiation exposure, resulting of the changes in the natural radioactive background [2].

The importance of the problems arising from the radioactive contamination requires the nascency of new sciences that integrate and investigate various aspects of contaminants with radio-nuclides, also new scientific disciplines are developing [3]. The radioecology is aimed to study the efficacy of migrating radioactive substances into the biosphere and the effects of ionizing radiation on living organisms. This study is considered to be a specific nature of the area on the surface of the dry land, which guarantees the living and conditions of living in the world and plays an extraordinary role in the future of the world [4], [5].

On the basis of the studies, a generalization of the information and the analysis of the results was developed a questionnaire, containing 20 questions. The interpellation included question and issues, covering the overall vision of the radiative background monitoring systems, population announcement, the actions of the competent authorities and their cooperation. Together with these radiation protection basics, the participants also expressed their opinion on the main factors that could lead to an accident and the way the radioactive particles, isotopes and rays are disseminated in terms of meteorological elements that influence them. The survey questions were chosen the way that they could fully cover the research problems from all the relevant points of view while in the same time not being boring for the participants. Increasing in the number of questions could be a danger that participants will not pay attention to the problems and those in the second part also. On the other hand, going to the other extreme with not enough questions, could not give the amount of information we need for the analysis and the subsequent conclusions.

The poll was conducted in February and March 2017 so that the information received is up to date. The resulting and aggregated information should not be considered as a constant because the situation changes dynamically, both in terms of the political situation in the region and the intentions of our neighbors regarding the sites that represent both the radiation risk and the meteorological elements that affect any radioactive contamination. Especially dynamic is the development of meteorological elements, which should be analyzed very thoroughly in the event of a nuclear accident or incident.

The study was conducted in three groups of participants. The first group consisted of radiation protection and nuclear physics specialists, who have a deeper understanding of the problems and their opinion has a greater impact. Due to the specificity of the problem, people from different institutions working in this or similar areas were involved here, but considering the research problem, their circle was not enough bigger - 38 people responded to the survey. In the selection of these specialists, I aspired to cover a wider range of institutions - Kozloduy NPP, HEI, BAS, Ministry of Interior, RNI at the Bulgarian Academy of Sciences and others. In the avoidance of subjective opinion, in the survey did not participated employees from Vassil Levski National Military University.

The second group of people included 
randomly selected individuals in different age groups and educational qualifications from all over the country. In this category there were 196 participants .

I also made a study among students in the first course at Vasil Levski National Military University and the results were also processed and analyzed independently. It was attended by 158 students who have received initial training in nuclear, chemical and biological protection and have some basic knowledge of nuclear accidents and their actions.

In summarizing of the results, the opinions of the three categories of people are considered separately, making only comparisons, but not a general presentation of the problem, because these issues are specific and need some acquaintance in the field of radiation protection in order to be able to respond appropriately.

The survey questionnaire is attached in this article.

After the survey was completed among all categories of learners, the results were processed by me and summarized in tabular form. Based on the summarized information there could be done some several statements:

1. The population is not aware of the measures that have to be taken by the competent state, municipal and other authorities in the event of a radiological emergency. This potential problem is dispayed with disregard and disinterest by the majority of the population, regardless of gender, age, ethnicity, education. Older people are more concerned about the problem than young participants. In their responding, participants who has a higher level of education, are more interested in the affected aspects of everyday life and also they are at least partially aware of the problems related to radiation protection, while those with secondary and lower education are ignorant and disinterested in the discussion done in the the consultation. Therefore the majority of the participants were not satisfied with the state's policy regarding the actions and the measures taken in case of a radiation accident.

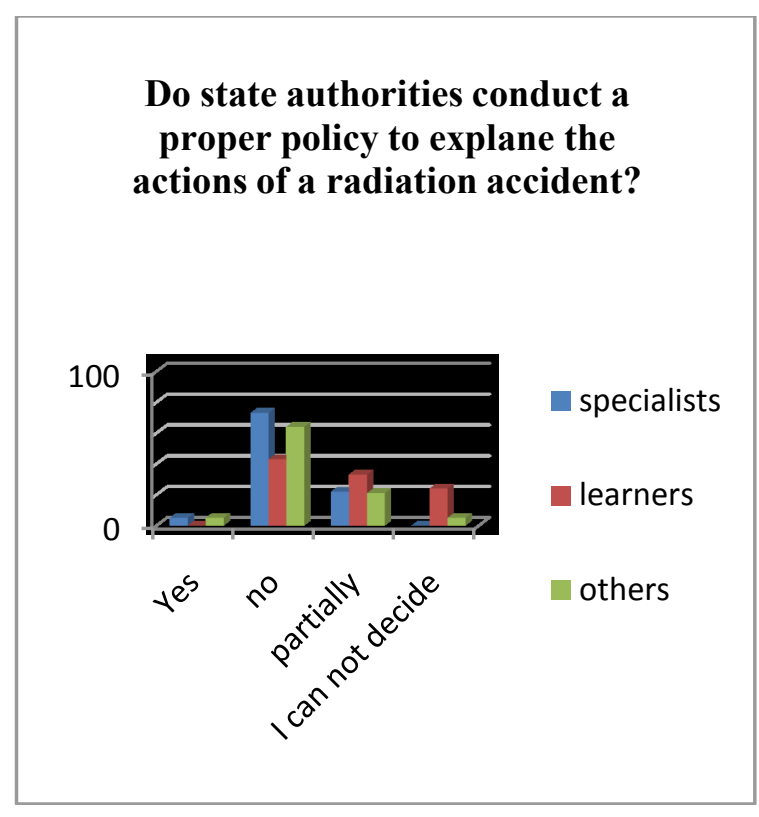

Figure 1: Poll results

2. There is a very large difference in the responses of the different groups of participants, regarding where the dangers of radioactive contamination come from and the possibility of nuclear accident. Here the learners and the random participants indicate Turkey as the greatest danger, while those who are more familiar with the problem have turned their attention to Romania. All participants unanimously state that Greece is not a nuclear threat to Bulgaria, but in response other indicate Russia, Ukraine, Hungary, the Czech Republic and Slovenia, but there is no other clear potential subject that would endanger our radiation safety. In spite of differences of opinion, Romania and Turkey are the main potential sources of Radioactive contamination. The opinion given is illustrated in Figure 2. 


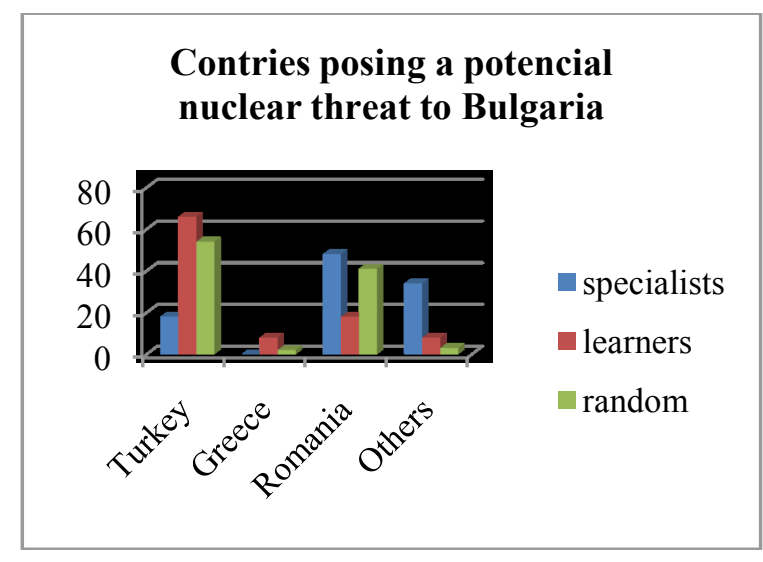

Figure 2: Bulgaria's threat of a radiological emergency

3. In detail examining of the main sites where nuclear facilities are or could be located, there is also a different degree of suspected danger, and the most serious , according to all participants, comes from Turkey, where the specialists give $37 \%$ and the other participants give 57-64\%. The other possible answers are given in roughly the same range regardless of the type of category. It is quite clear that the Kozloduy NPP is the most reliable nuclear facility in the region and that radioactive contamination is unlikely to occur (Figure 3.). When reading the survey data, it is clear that a large part can not assess whether the sites in Romania are potentially dangerous because of the lack of necessary information. This leads us to the conclusion that a large part of the population in Bulgaria does not know our neighboring countries and there is a lack of interest in enriching the knowledge of our safe living not only in terms of radiation safety but also in terms of other potential dangers and risks. These data can be found in Application 17 and these are also the reasons.

Although the referendum recently held in Bulgaria on whether developing nuclear power by building new capacities in the investigation I included similar question. The predominant response was connected to the upgrading of Belene NPP, with approval of $80 \%$ from nuclear and safety specialists, while for the random participants the positive response was $54 \%$. Accordingly, the disapproval was highest in the last category - $46 \%$, and in the experts it was only $20 \%$. With one reactor and second almost ready reactor, it is most reasonable to install them on the approved site and put into operation and in this way Bulgaria to regain its dominant position in the region of an energy exporter, otherwise we could become extremely energy dependent in the near future.

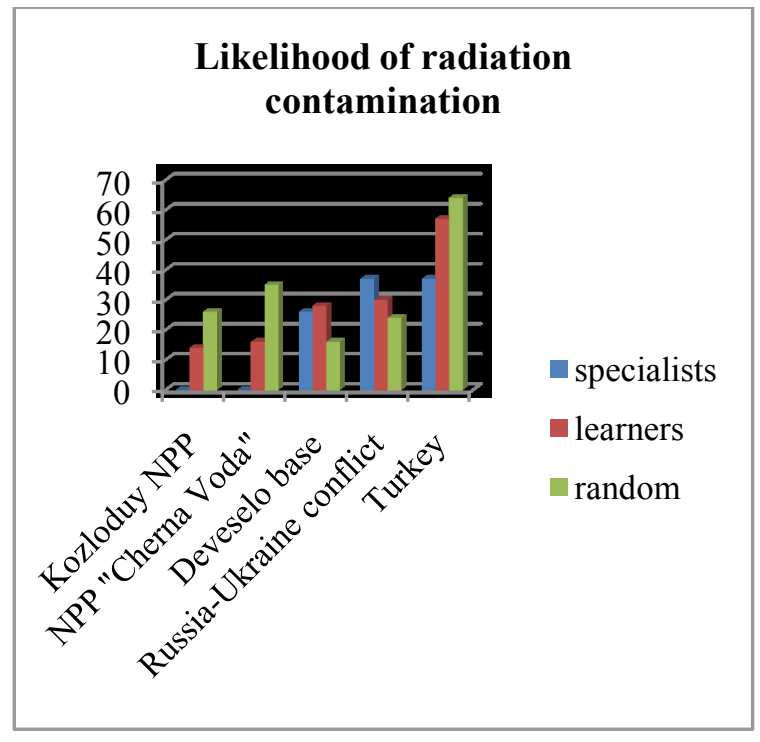

Figure 3: Potential carriers of radiation risk

4. The number of people familiar with the National Automated System for Continuous Control of the Radiochemical Background and the Radiation Population Forecasting System in the Event of a Major Nuclear Accident of the National Institute of Meteorology and Hydrology is too little. Even among the people who work in this area or around these problems, they are not so prepared for information to fulfill their direct duties. In the consultation, an often comment was that it is not in their direct duties and I they do not care. The percentage of people familiar with the systems varied between $2 \%$ and $26 \%$, which is a very low percentage. On this basis, a high percentage of people who have responded positively to the effectiveness of these systems can not be expected. More 
than half can not assess the level of coordination between organizations for monitoring the radiation situation and manage the activity in a situation of increased radioactive background and take measures to reduce and limit of the negative impact over people and environment.

The generalization of responses to the issues of coordination of the responsible authorities and agencies gives us a real picture of the population's interest in the real radiation situation, how it is monitored and what actions should be taken to reduce the negative impact. In this respect, the competent authorities need necessarily to improve their work among the population and their coordination. Only in this way they would weigh in their place and observe their work, raise their authority, and the population would believe in their actions.

Another aspect here, the predominant is again "I can not assess", which is indicative of the fact that a large part of the experts can not understand the real picture of the state of coordination between the most important authorities in the field of radiation protection. It is imperative for these important units for the state to become professionals, and not to become a continuous rocad of structures and performers, depending on the political situation. For example, I could give Italy, where, despite frequent political changes and elections, the Secretary of the Ministry of Foreign Affairs has been in charge for more than 30 years, and this creates the security of the institution he represents.

Figure 4 shows the assessment of the coordination between the responsible radiation monitoring institutions, according to the participants.

Similar is the picture in the assessment of the coordination between the departments which they announce when changing the radiation situation on the territory of Bulgaria. There is a peculiarity in responding learners - their opinions are almost equally divided between the four answers.

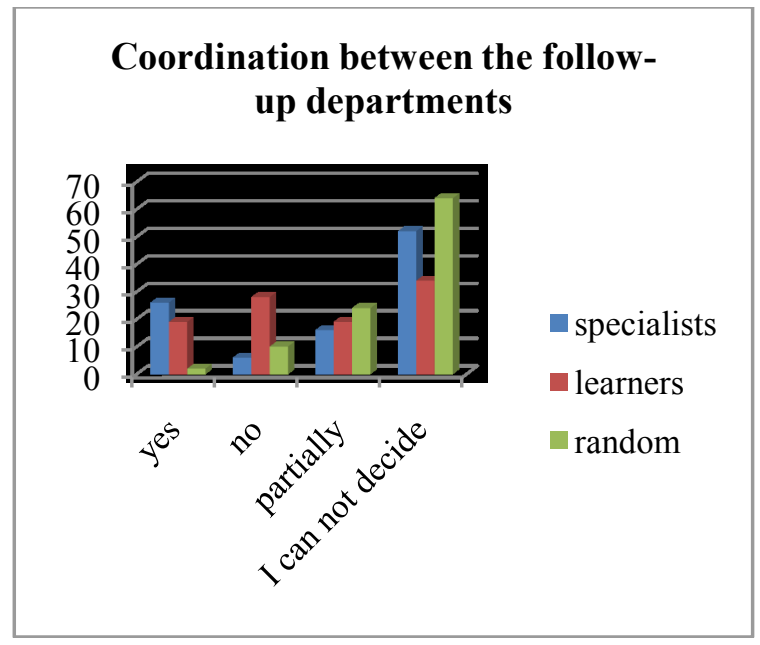

Figure 4: Coordination between departments that monitor the radiation situation

The explanation for this is due to the fact that they have recently received training on nuclear, chemical and biological accidents, theyhave visited the radiation and other protection enforcement at the current directorate of the Ministry of Interior and the Ministry of Interior and now they observe the situation under the impressions of the narrations of the professionals working there. In the other two categories, the fourth answer is very clear, namely "I can not assess". This is shown in Figure 5.

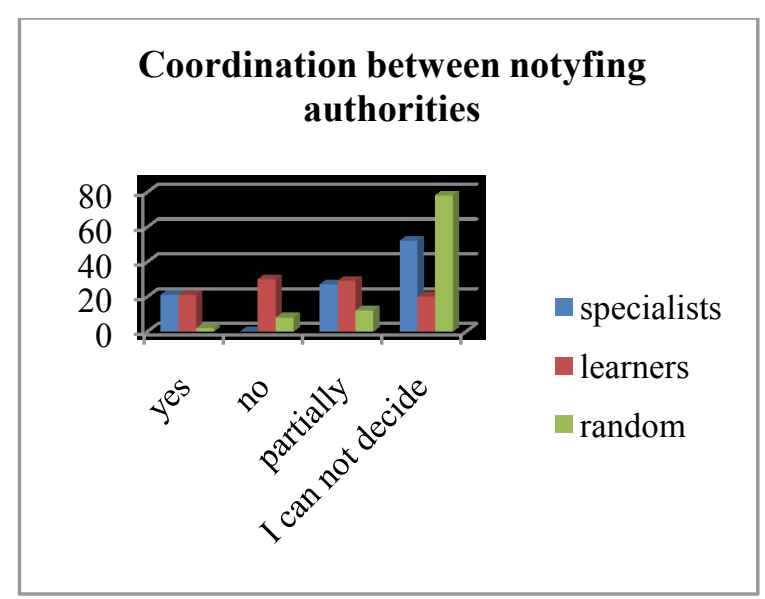

Figure 5: Coordination between notifying authorities when changing the radiation situation 
All inquiries about the need for more and better quality exercises and annual training of staff responsible for monitoring the radiation situation, and especially for government, local authorities and other non-governmental or voluntary organizations, are all categorical.

5. The majority of participants from the second and third groups did not make suggestions but there are also very reasonable ones. Together with the suggestions of those working in the field, we can bring them to the following generic proposals:

- The need for more quality annual exercises of all responsible institutions;

- Improving the interaction between followup and disclosure organizations;

- Conducting seminars and refreshing and effective employees training;

- To have updated and accessible information on the radiation situation by explaining to the competent authorities and the media where and how the population will receive it;

- In the current state of the art, in the announcement to include in addition to national television and radio and other electronic media and mobile operators, this is regulated by the law;

- Increase control points for monitoring the radiation background, taking into account the research and analysis.

\section{Conclusions:}

1. It is necessary to consolidate the activities of the organizations managing, servicing and using the available radioactive background control systems and public announcement of a nuclear incident, if there is needed. It is necessary to have reliable independent relationships between all the institutions that are responsible, controlling and acting in case of an emergency radiation situation.

2. Carrying out organizational changes in the controlling institutions and the formation of very good communication at all levels in response to the growing threats to national security from an incident or accident with radiological consequences and the need for adequate guidance of the competent authorities in the event of a radiation situation.

3. Creating operational capabilities at national and international level by trained empoyees and modular teams with wide capabilities and relative independance. In this direction, the first steps have been taken, there is that kind of teams and new equipment is bought, but is it not sufficient.

4. Research shows that specialists, responsible for the radiation protection at secondary and lower levels are not theoretically and practically prepared and the conducted studies are not effective. It is necessary for these specialists to undergo new training courses annually for both radiation accident and other possible accidents. This would help the increasing of their knowledge, skills and competences. The management of NASCRGF is carried out professionally, according to the requirements of the international organizations and our and international legislation. There is a need of expansion in the team of specialists, working to monitor the radiation background in Bulgaria, as well as improving their financial and resource security.

\section{Directions for further work:}

1. On the basis of the studies, researches, analyzes and evaluations carried out, the development of the issue under consideration should be continued, including other potential sources of ionizing radiation, located close to our territory and having a lower exposure.

2. Improvement of the examined model from the point of view of the impact of meteorological elements, by including the movement of air masses and other heights above the ground. This will provide better picture of the impact of potentially hazardous sites on the radioactive background in our territory. 


\section{References}

[1] Dolchinkov N. T., N. B. Nichev, Characteristics of radiation, Revista academiei fortelor terestre „Nicolae Bãlcescu”, Sibiu,Rumania, no.2(82)/2016, ISSN 2247-840X ISSN-L = 1582-6384 pp. 184-189;

[2] Dolchinkov N. T., N. B. Nichev, Structure and Management of the National Automated System for Permanent Control of the Radiation Gamma Background in Bulgaria, De gruyter open, Land Forces Academy Review, Vol. XXII, No 2(86), 2017, Sibiu, Romania, pp 115-121;

[3] Vasilev D., Radioecology, Titus Consult. Sofia, 2005, pp 124-144;

[4] National Programme on disaster the 2014 -2018, the Council of Ministers, Sofia, 2011;

[5] Annual Report NRA, the Council of Ministers, Sofia, 2015. 